\title{
Sponge distribution and the presence of photosymbionts in Moorea, French Polynesia
}

Christopher J Freeman, Cole G Easson

Photosymbionts play an important role in the ecology and evolution of diverse host species within the marine environment. Although sponge-photosymbiont interactions have been well described from geographically disparate sites worldwide, our understanding of these interactions from shallow water systems within French Polynesia is limited. We surveyed diverse habitats around the north coast of Moorea, French Polynesia and screened sponges for the presence of photosymbionts. Overall sponge abundance and diversity were low, with $<1 \%$ cover and only eight putative species identified by $28 \mathrm{~S}$ barcoding from surveys at 21 sites. Of these eight species, seven were found predominately in shaded or semicryptic habitats under overhangs or within caverns. Lendenfeldia chondrodes was the only species that supported a high abundance of photosymbionts and was also the only species found in exposed, illuminated habitats. Interestingly, L. chondrodes was found at 3 distinct sites, with a massive, fan shaped growth form at two of the lagoon sites and a thin, encrusting growth form within a bay site. These two growth forms differed in their photosymbiont abundance, with massive individuals of $L$. chondrodes having higher photosymbiont abundance than encrusting individuals from the bay. We present evidence that some sponges from French Polynesia support abundant photosymbiont communities and provide initial support for the role of these communities in host ecology. 
1 Sponge distribution and the presence of photosymbionts in Moorea, French Polynesia

2 Christopher J. Freeman ${ }^{1,2}$ and Cole G. Easson ${ }^{3,4}$

$3 \quad{ }^{1}$ Smithsonian Marine Station, Fort Pierce, Florida, USA

$4{ }^{2}$ IRCP, Institute for Pacific Coral Reefs, Labex Corail, BP1013 Papetoai, 98729 Moorea,

5 French Polynesia

$6{ }^{3}$ Nova Southeastern University, Halmos College of Natural Science and Oceanography, Dania

7 Beach, Florida, USA

$8{ }^{4}$ Department of Biology, University of Alabama at Birmingham, Birmingham, Alabama, USA

\section{Abstract}

10 Photosymbionts play an important role in the ecology and evolution of diverse host species

11 within the marine environment. Although sponge-photosymbiont interactions have been 
12 well described from geographically disparate sites worldwide, our understanding of these

13 interactions from shallow water systems within French Polynesia is limited. We surveyed

14 diverse habitats around the north coast of Moorea, French Polynesia and screened sponges

15 for the presence of photosymbionts. Overall sponge abundance and diversity were low, with

$16<1 \%$ cover and only eight putative species identified by $28 \mathrm{~S}$ barcoding from surveys at 21

17 sites. Of these eight species, seven were found predominately in shaded or semi-cryptic

18 habitats under overhangs or within caverns. Lendenfeldia chondrodes was the only species

19 that supported a high abundance of photosymbionts and was also the only species found in

20 exposed, illuminated habitats. Interestingly, L. chondrodes was found at 3 distinct sites, with

21 a massive, fan shaped growth form at two of the lagoon sites and a thin, encrusting growth

22 form within a bay site. These two growth forms differed in their photosymbiont abundance,

23 with massive individuals of $L$. chondrodes having higher photosymbiont abundance than

24 encrusting individuals from the bay. We present evidence that some sponges from French

25 Polynesia support abundant photosymbiont communities and provide initial support for the 26 role of these communities in host ecology.

\section{Introduction}

28 In the marine environment, symbiotic interactions fuel high species diversity in

29 otherwise nutrient poor systems like hydrothermal vents and coral reefs (Steinert,

30 Hentschel \& Hacker, 2000; Venn, Loram \& Douglas, 2008). On tropical reefs, the mutualism

31 between the dinoflagellate symbiont Symbiodinium and reef building corals has long

32 epitomized such an interaction (Muscatine \& Cernichiari, 1969; Muscatine \& Porter; 1977), 
33 but recent research has explored the functional role of photosynthetic microbes within

34 other dominant benthic fauna like octocorals (Baker et al., 2015) and sponges (Freeman et

35 al., 2013). Although autotrophic nutrition supplied by these photosymbionts can provide

36 more than enough $\mathrm{C}$ to compensate for holobiont (microbial symbiont and host)

37 metabolism (Venn, Loram \& Douglas, 2008; Usher, 2008), there is substantial variation in

38 the structure and function of these interactions across groups and species (Thacker $\mathcal{E}$

39 Freeman, 2012).

40 While reef building corals and octocorals host diverse communities of metabolically

41 distinct microbes (Knowlton \& Rohwer, 2003), many species of sponges support a microbial

42 diversity that rivals that found in other eukaryotic hosts (Thacker \& Freeman, 2012). The

43 structure of these interactions also varies across species, with high host specificity in

44 microbial community composition across sympatric host species (Thacker \& Freeman,

45 2012; Easson \& Thacker, 2014). This, coupled with the fact that host sponge identity

46 accounts for over $70 \%$ of the variation in the placement of an individual sponge within

47 bivariate $\left(\delta^{13} \mathrm{C}\right.$ and $\left.\delta^{15} \mathrm{~N}\right)$ isotopic "niche space", implies that microbial community

48 composition also plays an important role in the functional placement of a species in its

49 ecosystem (Freeman, Easson \& Baker, 2014).

50 By allowing sponge hosts to utilize inorganic sources of $\mathrm{C}$ and $\mathrm{N}$, abundant

51 photosymbiont communities also play a crucial role in sponge metabolism and impact the

52 overall nutritional benefit of these interactions to the host (Freeman $\&$ Thacker, 2011;

53 Freeman et al., 2013; Freeman, Easson \& Baker, 2014). Although sponge-photosymbiont

54 interactions have been widely reported in disparate geographic areas ranging from the

55 Great Barrier Reef (Wilkinson, 1983), Palau and Guam (Ridley, Faulkner \& Haygood, 2005;

56 Usher, 2008), Western Australia (Lemloh et al., 2009), Africa (Steindler, Beer \& Ilan, 2002), 
57 the Red Sea and Mediterranean (Wilkinson \& Fay, 1979; Usher, 2008), and the Caribbean

58 (Erwin \& Thacker, 2007; Freeman \& Thacker, 2011; Easson \& Thacker, 2014), limited data

59 exists on the prevalence of these interactions in other locations. For instance, despite the

60 fact that over 75 species of sponges have been previously reported in the Society and

61 Marquesas Islands of French Polynesia, the presence of photosymbiont hosting species is

62 largely based on anecdotal evidence that many of the species catalogued are from orders

63 dominated by "phototrophic" species (Hall et al., 2013). In addition, such assertions may not

64 be accurate, as the presence of photosymbionts can be variable even among species within a

65 genus and may thus vary substantially at higher taxonomic levels (Erwin \& Thacker, 2007).

66 To identify sponge species hosting photosymbiont communities in Moorea, French

67 Polynesia and describe the general habitat in which they are found, we conducted surveys

68 across diverse habitats and environmental conditions in bays, lagoons, and along the reef

69 slope on the northern coast of Moorea. Surveys included both man-made and natural

70 substrates, as well as under overhangs and semi-cryptic habitats. Sponges were identified

71 by obtaining a partial 28S rRNA gene sequence (Thacker et al., 2013, Erpenbeck et al., 2015)

72 and screened for the abundance of photosymbionts by chlorophyll $a$ analysis (Erwin $\mathcal{E}$

73 Thacker, 2007).

\section{Materials and Methods}

\section{Sample collection}

76 We surveyed 21 sites along the northern coast of Moorea, French Polynesia (see

77 Schrimm, Buscail \& Adjeroud, 2004 for a detailed description of the island) using a

78 combination of SCUBA and snorkeling (Figure 1). Sites included locations previously

79 reported to support sponge communities (Adjeroud \& Salvat, 1996; Adjeroud, 1997; 
80 Desmet, 2009; Hall et al., 2013) and also sites that were selected haphazardly by satellite

81 images and word of mouth from local researchers. To include both diverse habitats and

82 substrate types, we surveyed bay and lagoon sites, including the motu (an independent set

83 of islands within the lagoon), reef crest, channel openings, near beaches, reef slopes, and

84 docks/man-made structures (Figure 1; Table 1). Initial transects revealed that average

85 sponge cover was $<1 \%$, with coral or bare rock as the most common substrate. To

86 adequately sample sponge species in this area, we therefore adapted our methods and

87 surveyed sites by a two-diver swimming census method. Using this method, when a sponge

88 was observed, a small $\left(3-6 \mathrm{~cm}^{3}\right)$ sample was collected using a sharp dive knife and placed

89 into an individual sealed bag. Once on the boat, samples were stored on ice for transit back

90 to the Centre de Recherches Insulaires et Observatoire de L'Environment (CRIOBE) research

91 station. At CRIOBE, samples were photographed and two subsamples were taken. The first

92 subsample was preserved in $95 \% \mathrm{EtOH}$ for taxonomic identification via $28 \mathrm{~S}$ barcoding. The

93 use of 28S barcoding for sponge molecular taxonomy has increased in recent years (Thacker

94 et al., 2013, Erpenbeck et al., 2015), and while species-level taxonomic resolution may be

95 limited using this marker, it is not uncommon for sponges of French Polynesia to be

96 identified to only genus via morphological characters alone (Adjeroud \& Salvat, 1996;

97 Adjeroud, 1997; Desmet, 2009; Hall et al., 2013). We therefore propose that 28S barcoding

98 provides comparable taxonomic resolution to morphology-based studies in this area and,

99 importantly, also provides a comparatively rapid, effective, and objective comparison of

100 specimens collected across sites that may have slightly different morphologies. Because of

101 this, we have intentionally restricted our identifications to $28 \mathrm{~S}$ barcoding. The second

102 subsample was frozen for chlorophyll $a$ analysis. Permits for sponge collection and export

103 were obtained from the Institute for Pacific Coral Reefs (IRCP) and the Haut-commissariat 
104 de la République en Polynésia Francaise. Representative vouchers of these sponges are

105 stored at the Smithsonian Marine Station in Fort Pierce, Florida.

106 DNA extraction, PCR amplification, and sequencing

107 A total of 40 collected specimens were sequenced to obtain a molecular barcode.

108 Genomic DNA was extracted from ethanol-preserved samples using the PowerSoil DNA

109 extraction kit (MoBio), following the manufacturer's protocol. The oligonucleotide primers

110 SP635F and SP1411R were used to amplify a portion of the 28S ribosomal subunit (Thacker

111 et al., 2013), yielding an approximately 650bp fragment. PCR reaction products were gel-

112 purified and cleaned using the Wizard PCR Preps DNA Purification System (Promega).

113 Forward and reverse sequencing reactions were performed at the University of Alabama at

114 Birmingham (UAB) Center for AIDS Research (CFAR) DNA Sequencing Core Facility. Forward

115 and reverse sequences were then compared to ensure the accuracy of sequencing reactions

116 in CodonCode Aligner software (CodonCode) and Geneious (version 6.1.8, Biomatters

117 Limited), yielding a final consensus sequence for each voucher specimen A representative

118 sequence for each species is archived in GenBank under accession numbers KU746954 to

119 KU746961.

120 Phylogenetic analyses and species identification

121 Phylogenetic relatedness among surveyed sponge species was assessed using a

122 phylogeny constructed from a partitioned alignment of gene sequences from 40 collected

123 specimens and 44 GenBank sequences coding for the large (28S) nuclear ribosomal

124 subunits, which is a common marker used for molecular identification of sponge species

125 (Thacker et al., 2013). Sequences were aligned using the default options of MAFFT 7.245

126 (Katoh et al., 2002). We implemented a relaxed-clock model in MrBayes version 3.2.1

127 (Ronquist et al., 2012), using the CIPRES computational resources (Miller, Pfeiffer \& 
128 Schwartz, 2010) and constrained sponges in the class Calcarea as an outgroup using the

129 independent gamma rate relaxed clock model with a birth-death process (Aris-Brosou \&

130 Yang 2003). We included three parallel runs of 10 million generations, each using four

131 Markov chains and sampling every 100 generations. A consensus phylogeny of the three

132 parallel runs was summarized following a burn-in of $25 \%$. Sponge specimens were

133 ultimately identified to the lowest possible taxonomic level using the 28S genetic marker.

134 Chlorophyll a analysis

135 At the Smithsonian Marine Station, frozen sponge samples were lyophilized overnight,

136 ground to a fine powder, and weighed to the nearest 0.001 g. To quantify photosymbiont

137 abundance, chlorophyll $a(\operatorname{chl} a)$ analysis was carried out as in Erwin $\&$ Thacker (2007) and

138 Freeman, Easson \& Baker (2014). In short, dried sponge tissue was extracted in $90 \%$

139 acetone overnight at $4^{\circ} \mathrm{C}$ and the concentration of chl $a$ was quantified by measuring the

140 absorbance of these extracts at 750, 664, 647, and $630 \mathrm{~nm}$ and applying equations from

141 Parsons, Maita \& Lalli (1984). Chlorophyll $a$ values were not obtained for Dysidea sp. from

142 Kaveka dock because these sponge individuals were too small to allow for both taxonomic

143 vouchers and chl $a$ samples to be taken. We compared differences in mean chl $a$

144 concentrations using an Analysis of Variance (ANOVA; Systat, v. 11). Pairwise comparisons

145 of mean chl a concentrations between the three $L$. chondrodes populations and between $L$.

146 chondrodes and the low chl a samples were carried out using the Fisher's least significant

147 difference (LSD) post hoc test.

\section{Results}

149 Almost all specimens were from the class Demospongiae, with only one species from

150 Calcarea that closely matched Leucetta sp. Within Demospongiae, sequenced specimens

151 spanned all three subclasses (Heteroscleromorpha, Keratosa, Verongimorpha), and 5 
152 sponge orders within these subclasses (Hadromerida, Spirophorida, Haplosclerida,

153 Verongida, Dictyoceratida). Many of these specimens were genetically similar to members

154 of genera previously reported in French Polynesia. For instance, CB\# 1 to 5 (Cooks Bay,

155 Figures 1 and 2) were similar to species from the genus Leucetta sp. (Adjeroud \& Salvat,

156 1996; Adjeroud, 1997; Hall et al., 2013; Figure 3), OB2\# 1 (Opunohu Bay 2, Figures 1 and 2)

157 was similar to Cinachyrella sp. (Hall et al., 2013; Figure 3), IC\# 1 to 3 and KD\# 3 and 4

158 (Intercontinental Lagoon and Kaveka Dock; Figures 1 and 2), were identified as a Haliclona

159 sp. (Adjeroud, 1997; Hall et al., 2013; Figure 3), and KD\# 1 and 2 (Kaveka dock, Figure 1)

160 were most similar to a species within the genus Dysidea (Adjeroud \& Salvat, 1996;

161 Adjeroud, 1997; Hall et al., 2013; Figure 3). Other specimens were genetic matches to

162 sponges within the orders Verongida (S\&G\# 6 to 9), Dictyoceratida (S\&G\# 1 to 5 ), and the

163 subclass Heteroscleromorpha (OB1\#1 and 2) (Figures 1-3).

164 One species included several individuals of variable growth forms collected from

165 different locations (an encrusting growth form in Opunohu Bay [OB3\# 1 to 6] and a massive

166 fan-shaped growth form in the Motu Channel [MC\# 1 to 5] and Intercontinental Reef [ICR\#

1671 to 5]; Figures 1 and 2) that were shown to all be genetically identical (Figure 3). BLAST

168 results in GenBank revealed that these samples most closely matched Fasciospongia

169 chondrodes (also known as Lendenfeldia chondrodes). Histological comparisons indicated

170 internal fiber structure and thickness consistent with L. chondrodes (C. Diaz, personal

171 communication), and 16S and ITS cloning of all three morphotypes (Freeman \& Easson, in

172 prep) showed the presence of both Oscillatoria spongeliae and Synechocystis sp. symbionts,

173 a composition unique to L. chondrodes (as in L. chondrodes from Ridley, Faulkner \& Haygood,

174 2005). These three separate observations offer compelling evidence that these represent

175 different morphotypes of the same species. 
176 Most sponge species were found in shaded or otherwise semi-cryptic habitats,

177 except for Lendenfeldia chondrodes, which was found in exposed locations at all three sites.

178 Interestingly, there was a wide range of chlorophyll $a$ values across sponge samples

179 (Analysis of Variance [ANOVA]: $F=65.270, p<0.001$; Figure 4), with six of the seven species

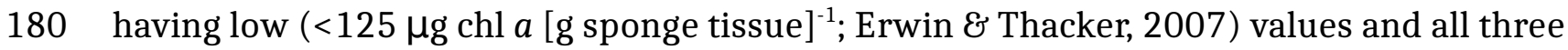

181 populations of Lendenfeldia chondrodes having significantly higher $(\sim 300-675 \mu \mathrm{g}$ chl $a$ [g

182 sponge tissue $]^{-1}$ ) $\operatorname{chl} a$ values than any of the other species (ANOVA followed by LSD

183 multiple pairwise comparisons: p<0.05; Figure 4). Chlorophyll $a$ values of L. chondrodes

184 varied across the three sites (ANOVA followed by LSD multiple pairwise comparisons:

$185 \mathrm{p}<0.05)$, with the encrusting, smooth growth form in Opunohu Bay having the lowest

186 photosymbiont abundance and the two massive, fan-shaped growth forms from the Motu

187 and the Intercontinental reef having chl $a$ values over $550 \mu \mathrm{g} \operatorname{chl} a$ (g sponge tissue) ${ }^{-1}$

188 (Figure 4). The highest chl $a$ values were found in the massive, fan shaped growth form from

189 the Intercontinental reef.

190 Discussion

191 This study expands our understanding of sponge distribution in Moorea, French

192 Polynesia and provides initial quantitative evidence that some sponges in French Polynesia

193 host abundant photosymbiont communities. The overall sponge diversity throughout the

194 Society Islands has previously been shown to be around 40 species (identified as operation

195 taxonomic units [OTUs]; Hall et al., 2013), with up to 17 species across sites in Moorea (10

196 species: Adjeroud \& Salvat, 1996; 17 species: Adjeroud, 1997; 7 species: Desmet, $2009 ; 12$

197 species: Hall et al., 2013). Variation in overall sponge diversity reported from Moorea likely

198 reflects the fact that some studies survey deep sites (18-39 m; Hall et al., 2013), while

199 others restrict collections to bays (Adjeroud \& Salvat, 1996) or survey a wide variety of 
200 habitats and depths (Adjeroud, 1997). To search for photosymbiont-hosting sponges, our

201 surveys were generally restricted to shallow (<10 m deep) environments, but we sampled

202 across diverse environmental conditions in bays, lagoons, and channel openings (Adjeroud

203 \& Salvat, 1996; Adjeroud, 1997; Schrimm, Buscail \& Adjeroud, 2004).

204 Our qualitative estimates of $<1 \%$ sponge cover on shallow substrates around

205 Moorea approaches the lower range reported from other locations in the Pacific. For

206 instance, the abundance of individual sponge species was from $<1 \%$ to $\sim 10 \%$ in the

207 Wakatobi region of Indonesia, and the percent cover of the whole sponge community in this

208 region ranged from 10\% to over 50 \%, (Bell \& Smith, 2004; Bell et al., 2010), with over 100

209 sponges per $\mathrm{m}^{2}$ at some sites (Powell et al., 2014). Likewise, the total number of individual

210 sponges observed across a depth gradient from 5 to $40 \mathrm{~m}$ on Davies Reef on the Great

211 Barrier Reef (GBR) ranged from 25 to well over 2000 at a single site, with over ten

212 individuals per $\mathrm{m}^{2}$ at some sites (Wilkinson $\&$ Evans, 1989) and between 0.5 to ten sponge

213 individuals per $\mathrm{m}^{2}$ at sites across the entire GBR reef tract (Wilkinson, 1987). Sponge

214 abundance in Moorea is also substantially lower than that observed from most sites in the

215 Caribbean, where the percent cover of sponges above $15 \mathrm{~m}$ depth ranges from $0.6 \%$ to over

$21620 \%$ (Pawlik et al., 2015).

217 We found interesting trends in the distribution of sponges across sites. Species with

218 low photosymbiont abundance were found in semi-cryptic habitats underneath overhangs

219 and in caverns. In addition, the Haliclona sp. was found in high abundances on artificial

220 substrates surrounding the Intercontinental Hotel and on the pilings of the Hotel Kaveka

221 within Cooks Bay, and rarely on reefs. Whether this species preferentially settles on artificial

222 substrates or favors areas with potentially elevated nutrient levels remains to be tested. In

223 contrast, the three growth forms of Lendenfeldia chondrodes were all found on exposed 
224 substrates in generally well-lit environments. Together this certainly suggests that

225 environmental conditions are playing a role in the distribution of sponges in Moorea.

226 The distribution of sponges on Pacific reefs is commonly ascribed to environmental

227 conditions. In particular, across the Great Barrier Reef, the overall biomass of sponges

228 decreases as you move offshore and the presence of phototrophic sponges (obtaining at

229 least $50 \%$ of their energy requirements from photosynthetic symbionts) increases, with up

230 to $90 \%$ of sponges from offshore reefs being phototrophic (Wilkinson, 1987). Although we

231 found three sponges in the order Dictyoceratida (Hall et al., 2013), only Lendenfeldia

232 chondrodes had chl a concentrations that were high enough to suggest that it might be

233 phototrophic.

234 Unlike phototrophic sponges on the GBR, L. chondrodes was found at relatively

235 pristine lagoon sites, at a more turbid site close to development (Intercontinental Reef), and

236 within bays that are impacted by terrestrial sources of nutrients (Adjeroud \& Salvat, 1996;

237 Adjeroud, 1997; Schrimm, Buscail \& Adjeroud, 2004). In addition, while phototrophic

238 sponges in the Pacific typically have foliose, flattened plate or cup like growth forms to

239 maximize light exposure (Wilkinson, 1987), individuals of L. chondrodes in Moorea were

240 either thinly encrusting or encrusting with abundant vertical fingers, giving the sponge a

241 fan-shaped growth form (similar to L. chondrodes in Ridley et al., 2005; Figure 2). These two

242 growth forms appear to be intermediate along the continuum encompassing foliose plate

243 sponges from the GBR, encrusting and finger-like projections in sponges from Palau and

244 Guam, and some of the encrusting and generally amorphous or fan-shaped sponges that

245 host photosymbionts in the Caribbean (Thacker \& Starnes, 2003; Ridley et al., 2005;

246 Freeman \& Thacker, 2011; Freeman et al., 2013; Pawlik et al., 2015). 
248 including the sponge-specific filamentous cyanobacteria Oscillatoria spongeliae, as well as 249 Synechocystis sp. (Ridley, Faulkner \& Haygood, 2005). This, coupled with our data showing 250 high photosymbiont abundance within individuals of L. chondrodes in Moorea, suggests that 251 this sponge is likely benefitting from this association. Additional work is underway to assess 252 the productivity of this species and determine if their internal photosymbionts are indeed 253 capable of more than compensating for host and symbiont metabolism (Freeman et al., 254 2013; Pawlik et al., 2015). Regardless of its status as a phototrophic species, L. chondrodes 255 was one of the dominant species across sites, suggesting that the presence of 256 photosymbionts may allow this species to survive and grow across more diverse habitats 257 than species that do not host photosymbionts and are largely restricted to refugia.

258 It is important to mention that cyanobacteria may acclimate to local conditions by 259 increasing or decreasing the chl $a$ concentrations within each cell (Six et al., 2014). Despite 260 this, we anticipate that it is unlikely that variation in chl $a$ concentration per cell is 261 structuring the vast differences between Lendenfeldia chondrodes and the other species in 262 this study that have chl $a$ values ranging from $1.5 \%$ to $28 \%$ of the chl $a$ values of $L$. 263 chondrodes from Opunohu Bay and 0.7 to $13.5 \%$ of the chl $a$ values of $L$. chondrodes from 264 the Intercontinental Reef site. In addition, while cyanobacterial cell counts performed in 265 conjunction with traditional chl a pigment analyses may allow for a more robust estimate of 266 chl $a$ per cell, the difficulty in resolving and counting individual cells within the filaments of 267 Oscillatoria spongeliae via fluorescent microscopy has been demonstrated previously (Flatt 268 et al., 2005). Ongoing research is therefore aimed at determining how symbiont metabolism 269 varies across Lendenfeldia chondrodes collected from these three sites, and whether this 270 variation is correlated with these differences in chl $a$ concentration. 
272 Symbiodinium and Dinophysis, as well a member of the order Dinophyceae within three 273 sponge species from Moorea and Tahiti. Wecker et al. (2015) identified Symbiodinium and

274 other dinoflagellates by PCR screening, but without quantifying the abundance of these 275 symbionts via chl $a$ analyses or microscopy, it is difficult to resolve whether their presence 276 reflects a true symbiosis or just reflects a low abundance of these microbes in the sponge at 277 the time of sampling. In contrast, L. chondrodes from our study has been shown by 278 amplification of the 16S rRNA gene and transmission electron microscopy to host abundant 279 communities of sponge-specific cyanobacteria (Ridley, Faulkner \& Haygood, 2005). We thus 280 anticipate that elevated chl $a$ values in this species predominately reflect cyanobacterial 281 symbiont abundance and not Symbiodinium or other dinoflagellates.

282 In summary, photosymbionts may allow sponges like L. chondrodes to compete for 283 space in well-illuminated reef habitats, filling niches that are unavailable to other sponge 284 species (Freeman, Easson \& Baker, 2014). In Moorea, these sponges may also expand into 285 niches recently vacated by coral die-offs from crown-of thorns outbreaks (Kayal et al., 286 2012). Manipulative shading experiments and reciprocal transplants among these sites may 287 help to elucidate this further (Thacker \& Freeman, 2012). With recent evidence that the 288 functional placement of a sponge individual within an ecosystem may be driven by the 289 overall microbial community composition, however, additional work is needed to 290 investigate variation in the microbiomes of sponges from across French Polynesia.

\section{Acknowledgements}

292 We thank the staff and scientists at the CRIOBE research station on Moorea for their 293 incredible logistical support of this project. We also thank Dr. Cristina Diaz for her help in 
294 verifying the morphotypes of $L$ chondrodes. This is contribution number XXXX from the 295 Smithsonian Marine Station at Fort Pierce.

\section{References}

297 Adjeroud M. 1997. Factors influencing spatial patterns on coral reefs around Moorea, $298 \quad$ French Polynesia. Marine Ecology Progress Series 159:105-119.

299 Adjeroud M, Salvat B. 1996. Spatial patterns in biodiversity of a fringing reef community 300 along Opunohu Bay, Moorea, French Polynesia. Bulletin of Marine Science 59:175$301 \quad 187$.

302 Aris-Brosou S, Yang Z. 2003. Bayesian models of episodic evolution support a late 303 Precambrian explosive diversification of the Metazoa. Molecular Biology and $304 \quad$ Evolution 20:1947-1954.

305 Baker DM, Freeman CJ, Knowlton N, Thacker RW, Kim K, Fogel ML. 2015. Productivity links 306 morphology, symbiont specificity, and bleaching in the evolution of Caribbean 307 octocoral symbioses. The ISME Journal doi:10.1038.

308 Bell JJ, Smith D. 2004. Ecology of sponge assemblages (Porifera) in the Wakatobi region, 309 south-east Sulawesi, Indonesia: richness and abundance. Journal of the Marine $310 \quad$ Biological Association of the United Kingdom 84:581-591.

311 Bell JJ, Berman J, Jones T, Hepburn LJ. 2010. Variability in the spatial association patterns of 312 sponge assemblages in response to environmental heterogeneity. Marine Biology $313 \quad$ 157:2503-2509.

314 Desmet DN. 2009. Seeking sponges: distribution of exposed Porifera in Moorea, French 
315 Polynesia. University of California, Berkley Moorea Class: Biology and Geomorphology 316 of Tropical Islands.

317 Easson CG, Thacker RW. 2014. Phylogenetic signal in the community structure of host318 specific microbiomes of tropical marine sponges. Frontiers in Microbiology 5:1-11.

319 Erpenbeck D, Voigt O, Al-Aidaroos AM, Berumen ML, Büttner G, Catania D, Guirguis AN, 320 Paulay G, Schätzle S, Wörheide. 2015. Molecular biodiversity of Red Sea demosponges. 321 Marine Pollution Bulletin http://dx.doi.org/10.1016/j.marpolbul.2015.12.004.

322 Erwin PM, Thacker RW. 2007. Incidence and identity of photosynthetic symbionts in 323 Caribbean coral reef sponge assemblages. Journal of the Marine Biological Association $324 \quad$ of the United Kingdom 87:1683-1692.

325 Flatt PM, Gautschi JT, Thacker RW, Musafija-Girt M, Crews P, Gerwick WH. 2005.

326 Identification of the cellular site of polychlorinated peptide biosynthesis in the marine 327 sponge Dysidea (Lamellodysidea) herbacea and symbiotic cyanobacterium Oscillatoria spongeliae by CARD-FISH analysis. Marine Biology 147:761-774.

329 Freeman CJ, Thacker RW. 2011. Complex interactions between marine sponges and their 330 symbiotic microbial communities. Limnology and Oceanography 56:1577-1586.

331 Freeman CJ, Thacker RW, Baker DM, Fogel M. 2013. Quality or quantity: is nutrient transfer 332 driven more by symbiont identity and productivity than by symbiont abundance? The 333 ISME Journal 7:1116-1125.

334 Freeman CJ, Easson CG, Baker DM. 2014. Metabolic diversity and niche structure in sponges 335 from the Miskito Cays, Honduras. Peer J 2:e695.

336 Hall KA, Sutcliffe PR, Hooper JNA, Alencar A, Vacelet J, Pisera A, Petek S, Folcher E, Butscher 337 J, Orempuller J, Maihota N, Debitus C. 2013. Affinities of sponges (Porifera) of the 338 Marquesas and Society Islands, French Polynesia. Pacific Science 67: 493-511. 
339 Katoh, K, Misawa K, Kuma K, Miyata T. 2002. MAFFT: a novel method for rapid multiple

340 sequence alignment based on fast Fourier transform. Nucleic Acids Research

$341 \quad 30: 3059-3066$.

342 Kayal M, Vercelloni J, de Loma TL, Bosserelle P, Chancerelle Y, Geoffroy S, Stievenart C,

343 Michonneau F, Penin L, Planes S, Adjeroud M. 2012. Predator crown-of-thorns

344 starfish (Acanthaster planci) outbreak, mass mortality of corals, and cascading effects

$345 \quad$ on reef fish and benthic communities. PLos One 7:e47363, doi:

$346 \quad$ 10.1371/journal.pone.0047363.

347 Knowlton N, Rohwer F. 2003. Multispecies microbial mutualisms on coral reefs: the host as a 348 habitat. American Naturalist 162: S51-562.

349 Lemloh M, Fromont J, Brümmer F, Usher KM. 2009. Diversity and abundance of

350 photosynthetic sponges in temperate Western Australia. BMC Ecology 9:4.

351 Miller MA, Pfeiffer W, Schwartz T. 2010. “Creating the CIPRES Science Gateway for inference 352 of large phylogenetic trees" In Proceedings of the Gateway Computing Environments 353 Workshop (GCE) 14 Nov 2010, New Orleans, LA pp 1-8.

354 Muscatine L, Porter JW. 1977. Reef corals: mutualistic symbioses adapted to nutrient-poor 355 environments. BioScience 27:454-460.

356 Muscatine L, Cernichiari E. 1969. Assimilation of photosynthetic products of zooxanthellae $357 \quad$ by a reef coral. Biological Bulletin 137:506-523.

358 Parsons TR, Maita Y, Lalli CM. 1984. A manual of chemical and biological methods for 359 seawater analysis. Pergamon Press.

360 Pawlik JR, McMurray SE, Erwin P, Zea S. 2015. A review of evidence for food limitation of 361 sponges on Caribbean reefs. Marine Ecology Progress Series 519:265-283.

362 Powell A, Smith DJ, Hepburn LJ, Jones T, Berman J, Jompa J, Bell JJ. 2014. Reduced diversity 

future changes in environmental quality. PLos One 9: e85253. doi:10.1371/journal.pone.0085253.

366 Ridley CP, Faulkner DJ, Haygood MG. 2005. Investigation of Oscillatoria spongeliae367 dominated bacterial communities in four Dictyoceratid sponges. Applied and $368 \quad$ Environmental Microbiology 71:7366-7375.

369 Ridley CP, Bergquist PR, Harper MK, Faulkner DJ, Hooper JNA, Haygood MG. 2005.

370 Speciation and biosynthetic variation in four Dictyoceratid sponges and their 371 cyanobacterial symbiont, Oscillatoria spongeliae. Chemistry \& Biology 12:397-406.

372 Ronquist, F, Teslenko M, van der Mark P, Ayres DL, Darling A, Höhna S, Larget B, Liu L, 373 Suchard MA, Huelsenbeck JP. 2012. MrBayes 3.2: efficient Bayesian phylogenetic inference and model choice across a large model space. Systematic Biology 61:539composition of surface sediments in an insular coral reef ecosystem: Moorea, French Polynesia. Estuarine Coastal and Shelf Science 60: 515-528.

379 Six C, Thomas JC, Brahamsha B, Lemoine Y, Partenski F. 2004. Photophysiology of the marine 380 cyanobacterium Synechococcus sp. WH8102, a new model organism. Aquatic Microbial Ecology 35:17-29.

382 Steindler L, Beer S, Ilan M. 2002. Photosymbiosis in intertidal and subtidal tropical sponges. 383 Symbiosis 33:263-273.

384 Steinert M, Hentschel U, Hacker J. 2000. Symbiosis and pathogenesis: evolution of the 385 microbe-host interaction. Naturwissenschaften 87:1-11. 
386 Thacker RW, Starnes S. 2003. Host specificity of the symbiotic cyanobacterium Oscillatoria 387 spongeliae in marine sponges, Dysidea spp. Marine Biology 142:643-648.

388 Thacker RW, Freeman CJ. 2012 Sponge-microbe symbioses: Recent advances and new 389 directions. Advances in Marine Biology 62:57-111.

390 Thacker, RW, Hill AL, Hill MS, Redmond NE, Collins AG, Morrow CC, Spicer L, Carmack CA, 391 Zappe ME, Pohlmann D, Hall C, Diaz MC, Bangalore PV. 2013. Nearly complete 28S 392 rRNA gene sequences confirm new hypotheses of sponge evolution. Integrative and $393 \quad$ Comparative Biology 53:373-387.

394 Usher KM. 2008. The ecology and phylogeny of cyanobacterial symbionts in sponges. 395 Marine Ecology 29: 178-192.

396 Venn AA, Loram JE, Douglas AE. 2008. Photosynthetic symbioses in animals. Journal of 397 Experimental Botany 59:1069-1080.

398 Wecker P, Fournier A, Bosserelle P, Debitus C, Lecellier G, Berteaux-Lecellier V. 2015.

399 Dinoflagellate diversity among nudibranchs and sponges from French Polynesia:

$400 \quad$ Insights into associations and transfer. Comptes Rendus Biologies 338:278-283.

401 Wilkinson CR. 1983. Net primary productivity in coral reef sponges. Science 219:410-412.

402 Wilkinson CR. 1987. Productivity and abundance of large sponge populations on Flinders 403 Reef flats, Coral Sea. Coral Reefs 5:183-188.

404 Wilkinson CR, Fay P. 1979. Nitrogen fixation in coral reef sponges with symbiotic $405 \quad$ cyanobacteria. Nature 279:527-529.

406 Wilkinson CR, Evans E. 1989. Sponge distribution across Davies Reef, Great Barrier Reef, 407 relative to location, depth, and water movement. Coral Reefs 8:1-7. 
408 Table 1: Sites supporting sponge communities around Moorea, French Polynesia. Site 409 abbreviations correspond to labeled red markers in Figure 1 


\begin{tabular}{|c|c|c|c|c|}
\hline Site & Name & $\begin{array}{c}\text { GPS } \\
\text { Coordinates }\end{array}$ & Description & Sponge Species \\
\hline $\begin{array}{l}\text { SE } \\
G\end{array}$ & Spur and Groove & $\begin{array}{l}17^{\circ} 30^{\prime} 7.21^{\prime \prime S} \\
149^{\circ} 55^{\prime} 36.98^{\prime \prime} \\
W\end{array}$ & $\begin{array}{l}\text { 6-8 m deep, hardbottom, } \\
\text { high-energy }\end{array}$ & Verongid sp. and Dictyoceratida sp. \\
\hline MR & Motu Reef & $\begin{array}{l}17^{\circ} 29^{\prime} 16.50^{\prime \prime S} \\
149^{\circ} 55^{\prime} 7.73^{\prime \prime} \\
W\end{array}$ & $\begin{array}{l}\text { 1-2 m deep, coral heads, } \\
\text { hardbottom, sandy } \\
\text { habitat }\end{array}$ & $\begin{array}{l}\text { Lendenfeldia chondrodes (De Laubenfels, } \\
\text { 1954) massive fan morph }\end{array}$ \\
\hline MC & Motu Channel & $\begin{array}{l}17^{\circ} 29^{\prime} 20.37^{\prime \prime S} \\
149^{\circ} 54^{\prime} 52.47^{\prime \prime} \\
W\end{array}$ & $\begin{array}{l}2-4 \text { m deep, sandy } \\
\text { bottom, occasional coral } \\
\text { head and hard substrate, } \\
\text { high current }\end{array}$ & $\begin{array}{l}\text { Lendenfeldia chondrodes (De Laubenfels, } \\
\text { 1954) massive fan morph }\end{array}$ \\
\hline ICR & $\begin{array}{l}\text { Intercontinental } \\
\text { Reef }\end{array}$ & $\begin{array}{l}17^{\circ} 29^{\prime} 17.21^{\prime \prime S} \\
149^{\circ} 53^{\prime} 47.82^{\prime \prime} \\
W\end{array}$ & $\begin{array}{l}\text { 2-3 m deep, vertical wall } \\
\text { in channel, hard } \\
\text { substrate, moderate } \\
\text { current }\end{array}$ & $\begin{array}{l}\text { Lendenfeldia chondrodes (De Laubenfels, } \\
\text { 1954) massive fan morph }\end{array}$ \\
\hline ICL & $\begin{array}{l}\text { Intercontinental } \\
\text { Lagoon Wall }\end{array}$ & $\begin{array}{l}17^{\circ} 29^{\prime} 25.97^{\prime \prime S} \\
149^{\circ} 53^{\prime} 32.56^{\prime \prime} \\
W\end{array}$ & $\begin{array}{l}1 \text { m deep, artificial } \\
\text { concrete substrate }\end{array}$ & Haliclona sp. \\
\hline $\begin{array}{l}\text { OB } \\
3\end{array}$ & $\begin{array}{l}\text { Opunohu Bay Site } \\
3\end{array}$ & $\begin{array}{l}17^{\circ} 29^{\prime} 48.71^{\prime \prime S} \\
149^{\circ} 51^{\prime} 46.03^{\prime \prime} \\
W\end{array}$ & $\begin{array}{l}\text { 2-10 m deep, hard } \\
\text { substrate, overhangs } \\
\text { and high vertical relief, } \\
\text { moderate current }\end{array}$ & $\begin{array}{l}\text { Lendenfeldia chondrodes (De Laubenfels, } \\
\text { 1954) encrusting, smooth morph, Leucetta sp., } \\
\text { Heteroscleromorpha sp, Cinachyrella sp. }\end{array}$ \\
\hline $\begin{array}{l}\text { OB } \\
2\end{array}$ & $\begin{array}{l}\text { Opunohu Bay Site } \\
2\end{array}$ & $\begin{array}{l}17^{\circ} 29^{\prime} 53.60^{\prime \prime S} \\
149^{\circ} 51^{\prime} 42.36^{\prime \prime} \\
W\end{array}$ & $\begin{array}{l}\text { 2-10 m deep, hard } \\
\text { substrate, overhangs } \\
\text { and high vertical relief, } \\
\text { moderate current }\end{array}$ & $\begin{array}{l}\text { Lendenfeldia chondrodes (De Laubenfels, } \\
\text { 1954) encrusting, smooth morph, } \\
\text { Cinachyrella sp. }\end{array}$ \\
\hline $\begin{array}{l}\text { OB } \\
1\end{array}$ & $\begin{array}{l}\text { Opunohu Bay Site } \\
1\end{array}$ & $\begin{array}{l}17^{\circ} 30^{\prime} 19.68^{\prime \prime S} \\
149^{\circ} 51^{\prime} 29.17^{\prime \prime} \\
W\end{array}$ & $\begin{array}{l}\text { 3-5 m deep, hard } \\
\text { substrate, overhangs }\end{array}$ & $\begin{array}{l}\text { Lendenfeldia chondrodes (De Laubenfels, } \\
\text { 1954) encrusting, smooth morph, } \\
\text { Heteroscleromorpha sp., Cinachyrella sp., } \\
\text { Leucetta sp. }\end{array}$ \\
\hline $\mathrm{CB}$ & Cooks Bay & $\begin{array}{l}17^{\circ} 29^{\prime} 32.09^{\prime \prime S} \\
149^{\circ} 49^{\prime} 34.26^{\prime \prime} \\
W\end{array}$ & $\begin{array}{l}2-5 \text { m deep, hard } \\
\text { substrate, overhangs }\end{array}$ & $\begin{array}{l}\text { Lendenfeldia chondrodes (De Laubenfels, } \\
\text { 1954) encrusting, smooth morph, Leucetta sp., } \\
\text { Heteroscleromorpha sp. }\end{array}$ \\
\hline KD & $\begin{array}{l}\text { Kaveka Hotel } \\
\text { Dock }\end{array}$ & $\begin{array}{l}17^{\circ} 29^{\prime} 23.59^{\prime \prime S} \\
149^{\circ} 49^{\prime} 8.37^{\prime \prime} \\
W\end{array}$ & $\begin{array}{l}\text { 1-2 m deep, artificial } \\
\text { concrete substrate }\end{array}$ & Haliclona sp., Leucetta sp., Dysidea sp. \\
\hline
\end{tabular}




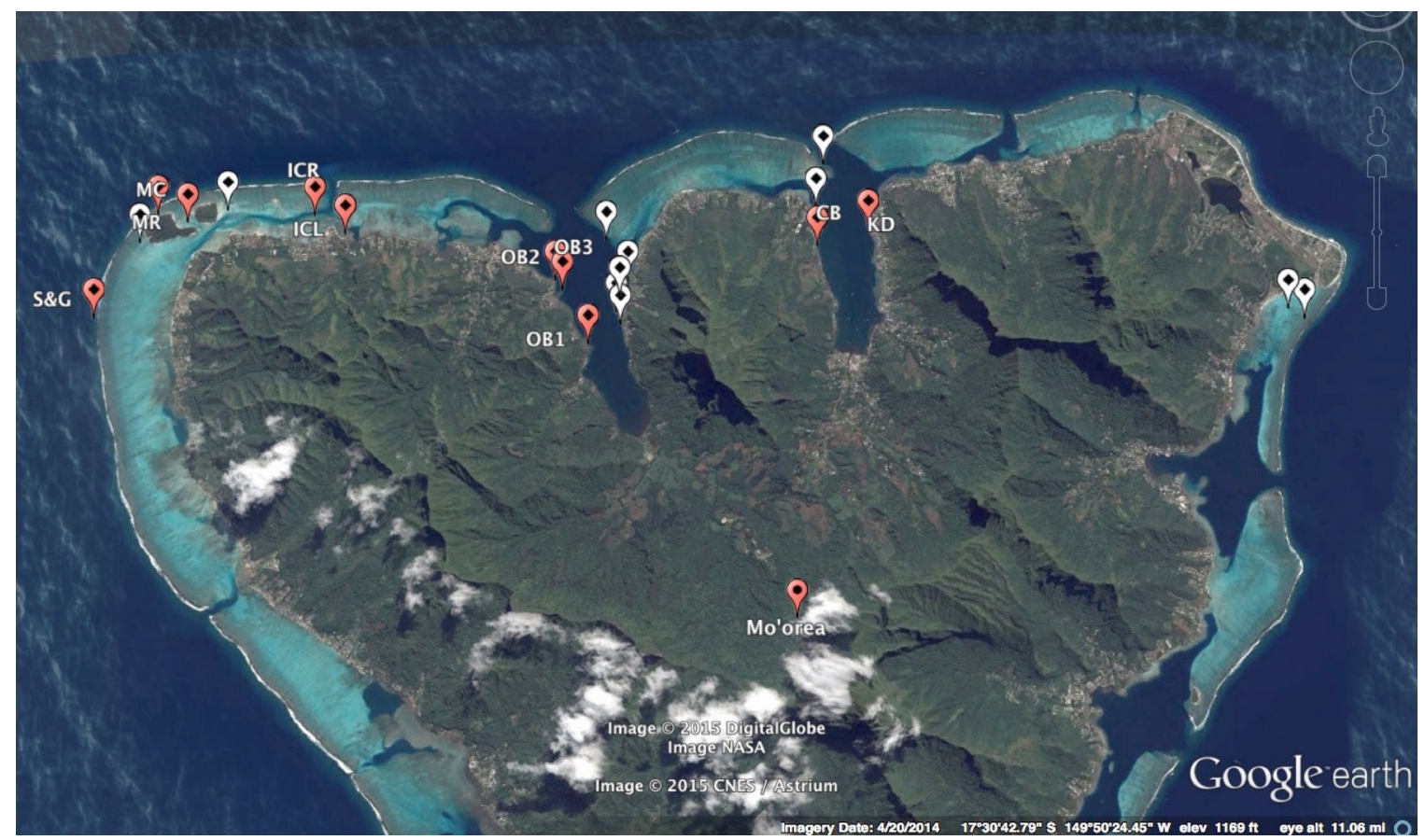

410 Figure 1: Map of sites surveyed along the northern coast of Moorea, French Polynesia.

411 Sponges were observed at sites represented by a red marker, while white markers denote

412 sites in which sponges were not observed. Abbreviations on red markers correspond to site

413 names in Table 1. Map data: Google, Digital Globe Image NASA and CNES/Astrium 


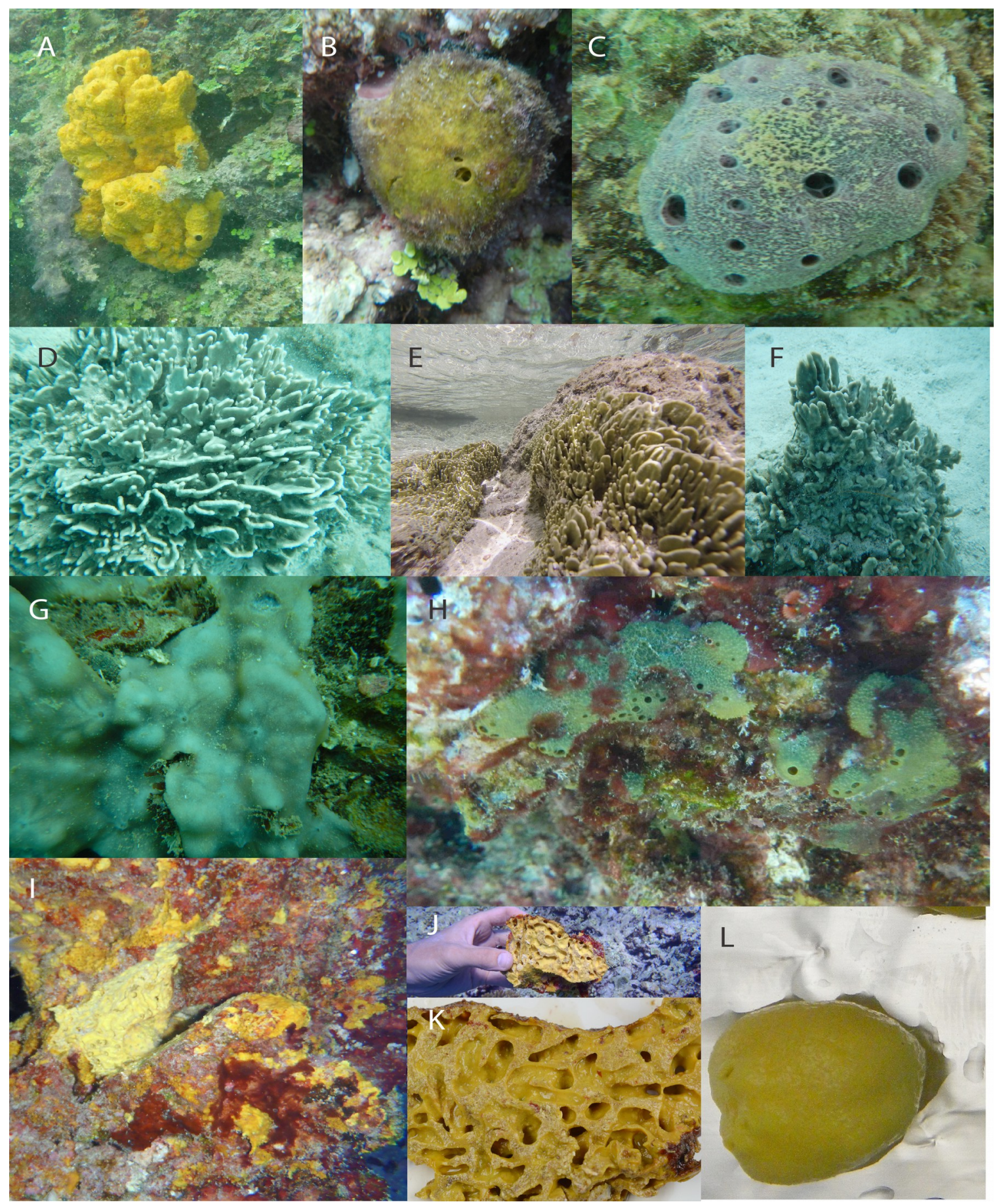

414 Figure 2: Photographs of sponges from Moorea, French Polynesia: Heteroscleromorpha sp.

415 from Opunohu Bay site \# 1 (A); Cinachyrella sp. from Opunohu Bay site \#2 (B); Haliclona sp.

416 from Intercontinental Lagoon Wall (C); Lendenfeldia chondrodes from Intercontinental Reef

417 (D), Motu Channel (E and F), and Opunohu Bay Site \#3 (G); Dictyoceratida sp. from the Spur 
418 and Groove site (H); Verongid sp. from Spur and Groove Site (I, J, and K); Leucetta sp. from

419 Cooks Bay (L). Photographs of Dysidea sp. from Kaveka Hotel Dock were not taken. 


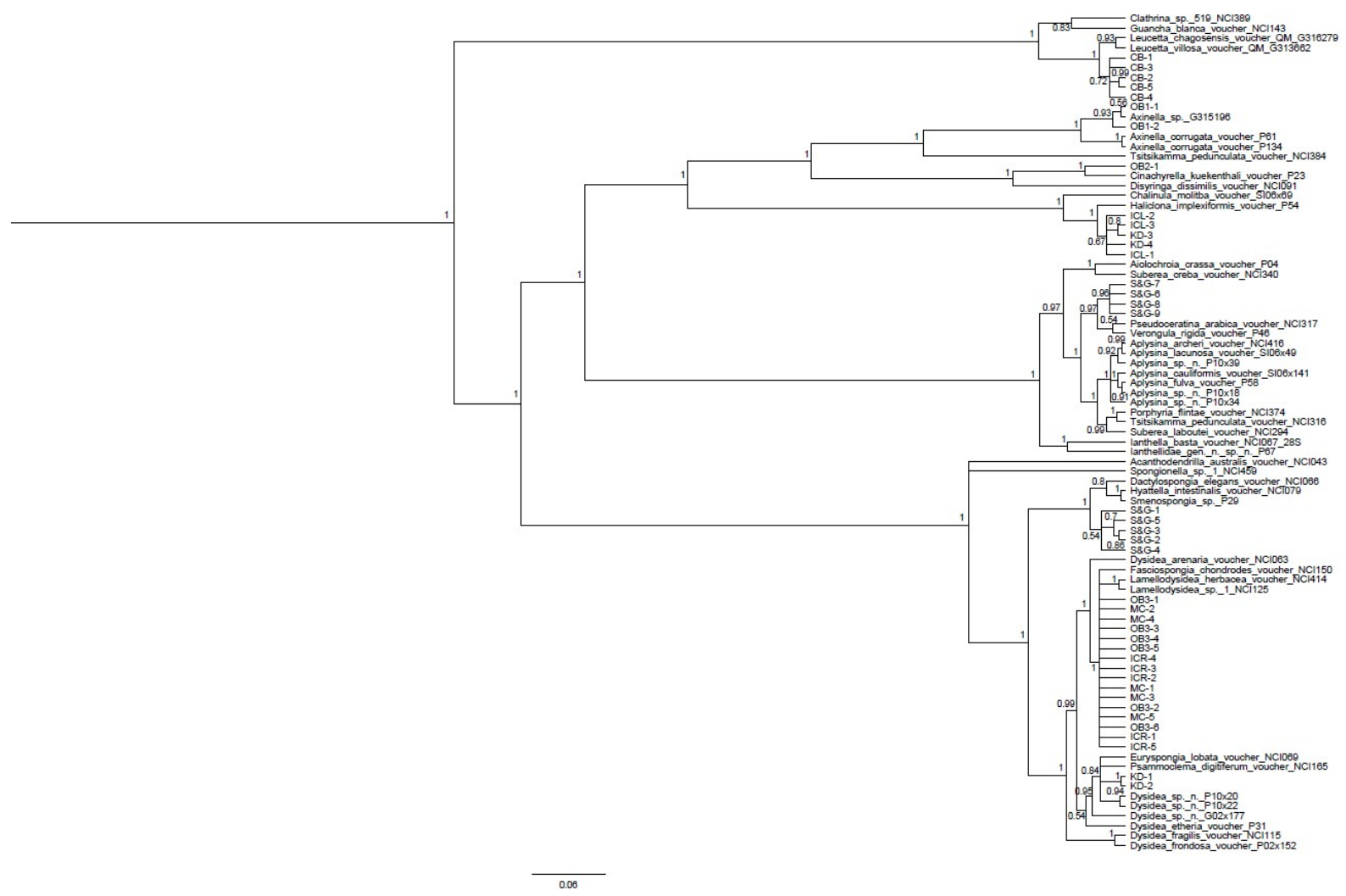

420 Figure 3: Bayesian 28S phylogeny of relationships among collected specimens and closely

421 related, previously sequenced specimens from GenBank. Scale bar indicates 0.06

422 substitutions per site. Posterior probabilities are shown for each node. 


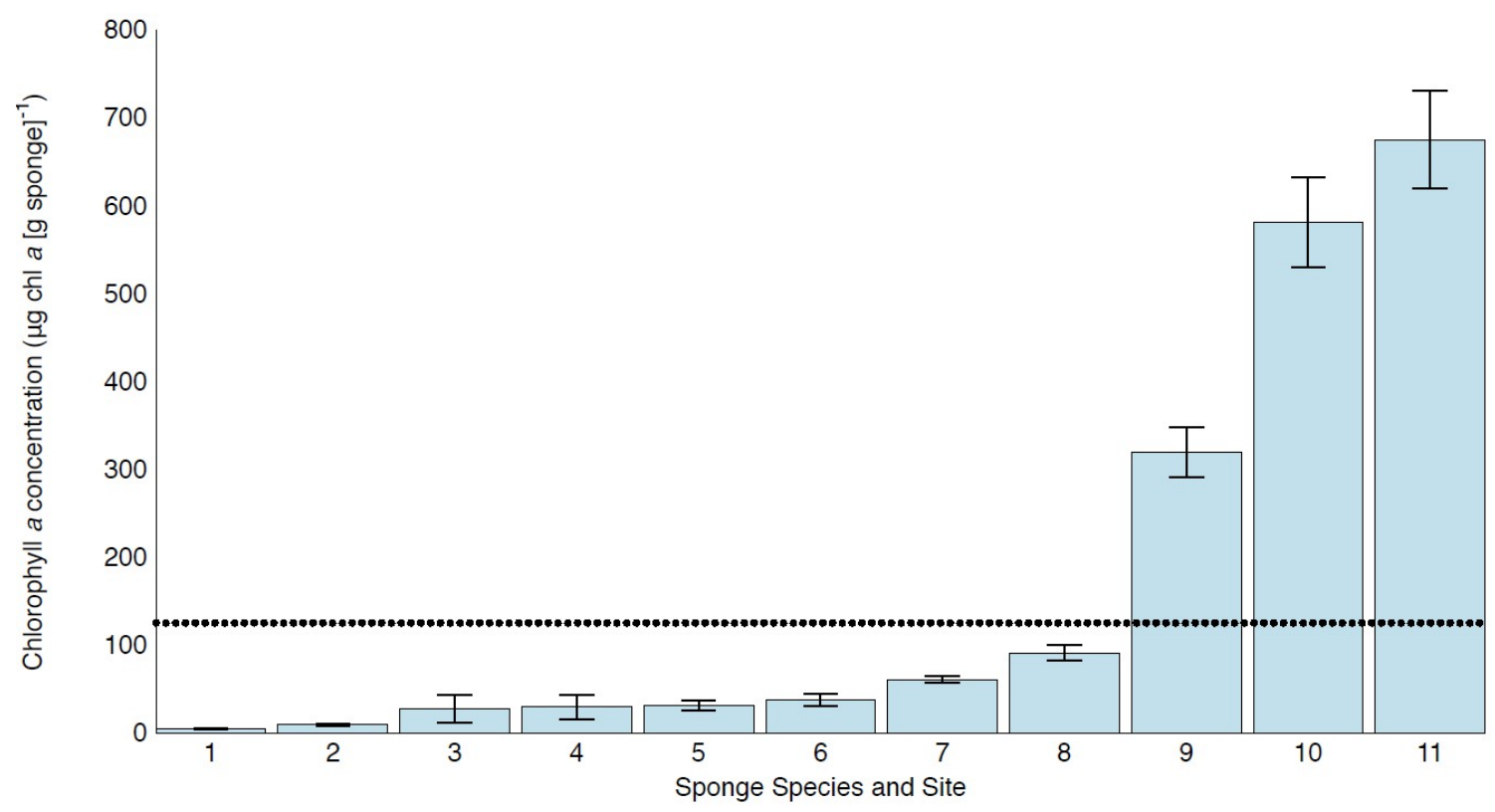

423 Figure 4: Mean ( \pm ) SE chlorophyll a concentration ( $\mu g$ chl a [g sponge tissue $]^{-1}$ ) across 424 seven sponge species from habitats around Moorea, French Polynesia. The dotted line at $425125 \mu \mathrm{g} c h l$ a (g sponge tissue) $)^{-1}$ denotes the separation between sponges hosting high (> 426 125) and low (< 125) photosymbiont communities (established by Erwin \& Thacker, 2007).

427 Sponge identifications and sites are: 1: Leucetta sp. from Kaveka Dock (KD), 2: Leucetta sp. 428 from Cooks Bay (CB), 3: Dictyoceratida sp. from Spur and Groove (SEG), 4:Verongid sp. from 429 Spur and Groove (SEG), 5: Cinachyrella sp. from Opunohu Bay (OB), 6: Heteroscleromorpha 430 sp. from Opunohu Bay (OB), 7: Haliclona sp. from Kaveka Dock (KD), 8: Haliclona sp. from 431 Intercontinental Lagoon (ICL), 9: Lendenfeldia chondrodes from Opunohu Bay (OB), 10: 432 Lendenfeldia chondrodes from Motu Channel (MC) and 11: Lendenfeldia chondrodes from 433 Intercontinental Reef (ICR). 